\title{
Chronic Alcohol Consumption Modulates the Clotting Time In Wistar Rats
}

\author{
Ekhoye E. I., Nwangwa E. K, Ugoji, A.E. \\ Department of Physiology, Faculty of Basic Medical Science, College of Health Science, Delta State University, \\ P.M.B 001, Abraka, Delta State, Nigeria
}

\begin{abstract}
The study investigated the changes in blood clotting time due to the effect of chronic consumption of alcohol. Thirty six (36) adult male Wistar rats were randomly divided into six groups of $A, B, C, D, E$ and $F$ $(n=6)$. Animals in experimental groups B, C and D were given $15 \%, 20 \%$ and $25 \%$ alcohol respectively by oral intubation for forty two (42) days, groups $E$ and $F$ received $25 \%$ alcohol each and after initial treatment alcohol was withdrawn for an additional twenty one (21) and forty two (42) days respectively, while group A (control) received equivalent volume of distilled water. In all groups, the blood samples were obtained by cardiac puncture under chloroform anaesthesia to determine clotting time. The study revealed significant $(p<0.05)$ increase in clotting time in the animals treated with alcohol while the clotting time decreased after subsequent alcohol withdrawal. Chronic of alcohol consumption therefore increases clotting time and its withdrawal returns the clotting time to normal level.
\end{abstract}

Keywords: Clotting time, Alcohol, Coagulation

\section{Introduction}

Coronary artery disease (CAD) is a major cause of morbidity and mortality in western industrialized countries. There are epidemiological studies which indicate that consumption of moderate quantities of alcohol reduce the morbidity and mortality from CAD (Moore and Pearson, 1986; Yano et al., 1977).

The mechanisms by which alcohol affects the cardiovascular system, beneficially or detrimentally, have been the target of research. Many epidemiologic studies have shown that moderate alcohol consumption can reduce the risk of heart disease and ischemic stroke by $20 \%$ to $60 \%$ and death of all causes by $10 \%$ to $20 \%$ (Lazarus et al, 1991). The underlying factors contributing to the protective or pathologic effects related to alcohol consumption are not well understood Studies that have investigated the role alcohol consumption play in preventing CAD found increases in high density lipoproteins (HDL) and antioxidants and decreases in the low density lipoproteins (LDL) (Friedman and Kimball, 1986; Klatsky et al., 1992). Reduction in the risk of CAD can be related to the prevention of clotting or thrombosis. It was found that alcohol decreases both platelet aggregation and the circulating fibrinogen level (Renaud and De Lorgeril, 1992). Coagulation factors, specifically fibrinogen and factor VII, (serum prothrombin conversion accelerator) have been implicated as risk factors for atherosclerotic diseases (Wilhelmsen et al., 1984; Meade et al., 1986). Several cross-sectional studies also have suggested an association between factor VIII and von Willebrand factor (vWF) with atherosclerotic heart disease, but other studies have found no association with heart disease (Sugrue et al., 1985; Myreng et al., 1986). Thus, a reduction in the risk of CAD can be related to the prevention of clotting or thrombosis, especially because $90 \%$ of patients with fatal myocardial infarction have associated coronary thrombosis. Studies have indicated that alcohol also directly affects hemostasis via a number of mechanisms, including modulation of plasma coagulation factors, fibrinolysis, and platelet function (Dimmitt et al., 1998; Hillbom and Neiman, 1988; Mikhailidis et al., 1986). Thus, individuals without a history of alcoholism might benefit from moderate consumption of alcohol. Although the association between moderate drinking and a lower risk of coronary artery disease has been well documented, the mechanisms by which alcohol causes these effects remains just as elusive as those underlying alcohol-related diseases. Therefore this study aims at accessing the effect of alcohol on the clotting time of adult Wistar rats.

\section{Materials And Methods}

Animal Handling

A total of thirty six (36) male adult Wistar albino rats $(160-180 \mathrm{~g})$ were used in this study and were raised in the Animal House Unit in the Faculty of Basic Medical Science, Delta State University, Nigeria. The animals were acclimatized for a period of two (2) week. During the acclimatization period, each group of rats were maintained in one cage and under standard, uniform husbandry conditions of light $(12 \mathrm{~h}$ light and $12 \mathrm{~h}$ darkness) and room temperature $\left(28-30^{\circ} \mathrm{C}\right)$ and they were fed with grower's mash produced by Bendel Feeds and Flour Mills Limited, Ewu, Nigeria. 


\section{Design of Experiment}

The animals were randomly divided into six (6) groups of six (6) rats each, as thus

Group $A=\quad$ Normal Control rats $(n=6)$

Group $\mathrm{B}=\quad 15 \%$ alcohol treated rats $(\mathrm{n}=6)$

Group $\mathrm{C}=\quad 20 \%$ alcohol treated rats $(\mathrm{n}=6)$

Group $\mathrm{D}=\quad 25 \%$ alcohol treated rats $(\mathrm{n}=6)$

The reversal experiment groups consist of

Group $\mathrm{E}=\quad 3$ weeks Reversal after $25 \%$ alcohol treatment $(\mathrm{n}=6)$

Group $\mathrm{F}=6$ weeks Reversal after $25 \%$ alcohol treatment $(\mathrm{n}=6)$

The choice of these concentrations of the treatment of alcohol was based on the knowledge that the respective maximum concentrations were not lethal to the animals. The treatment material was administered for a period of six (6) weeks. For the reversal experimental group, the administration of the treatment material was terminated at the end of six (6) weeks, and the rats returned to their usual normal feed and drinking water for additional three (3) and six (6) weeks respectively, before being sacrificed.

\section{Drug Administration}

The Alcohol in the form of ethanol was administered as a single intraperitoneal (IP) daily dose for a period of forty two (42) days, before being sacrificed. The required, calculated volume, $0.015 \mathrm{ml} / \mathrm{g}$ body weight of ethanol was administered slowly, over a period of 1 to 2 minutes according to specifications from Dare et al (2002).

\section{Collection of Samples}

The rats were first anaesthetize by using chloroform and sacrificed. Blood samples were collected directly from the heart, by cardiac puncture, into plain capillary tubes; the clotting time was calculated during this period.

\section{Clotting time}

Two capillary tubes were used simultaneously for each rat, as blood entered the capillary tubes, a stop watch was started. Both ends of the capillary tube were sealed immediately with plasticine and placed horizontally in the water bath. After one minute, small pieces is broken off every 30 seconds from the end which the blood started first and the capillary is resealed and replaced in the water bath. A clear white background is placed to be able to see the first fibrin strand. End point is marked by the presence of a white thin fibrin thread.

\section{Statistical Analysis}

Data from this study were represented as Mean \pm Standard deviation. Analytical software SPSS 17.00 version was used for Statistical analysis. The test of significance was carried out using Student's t-Test. A pvalue of less than 0.05 was considered statistically significant.

\section{Effect of Alcohol on Body Weight}

\section{Results}

For clotting to occur, the enzyme thrombin must be generated from the plasma precursor prothrombin. The thrombin then converts soluble fibrinogen into soluble fibrin. The time required for thrombin to be generated is a reflection of the clotting time. Clotting time maybe prolonged if the plasma concentration of prothrombin or some other factor is low. In this experiment, the effect of alcohol on the body weight was assessed. Changes in the body weight of alcohol treated rats were compared to those of the control rats. The body weights were measured on a four day interval. 


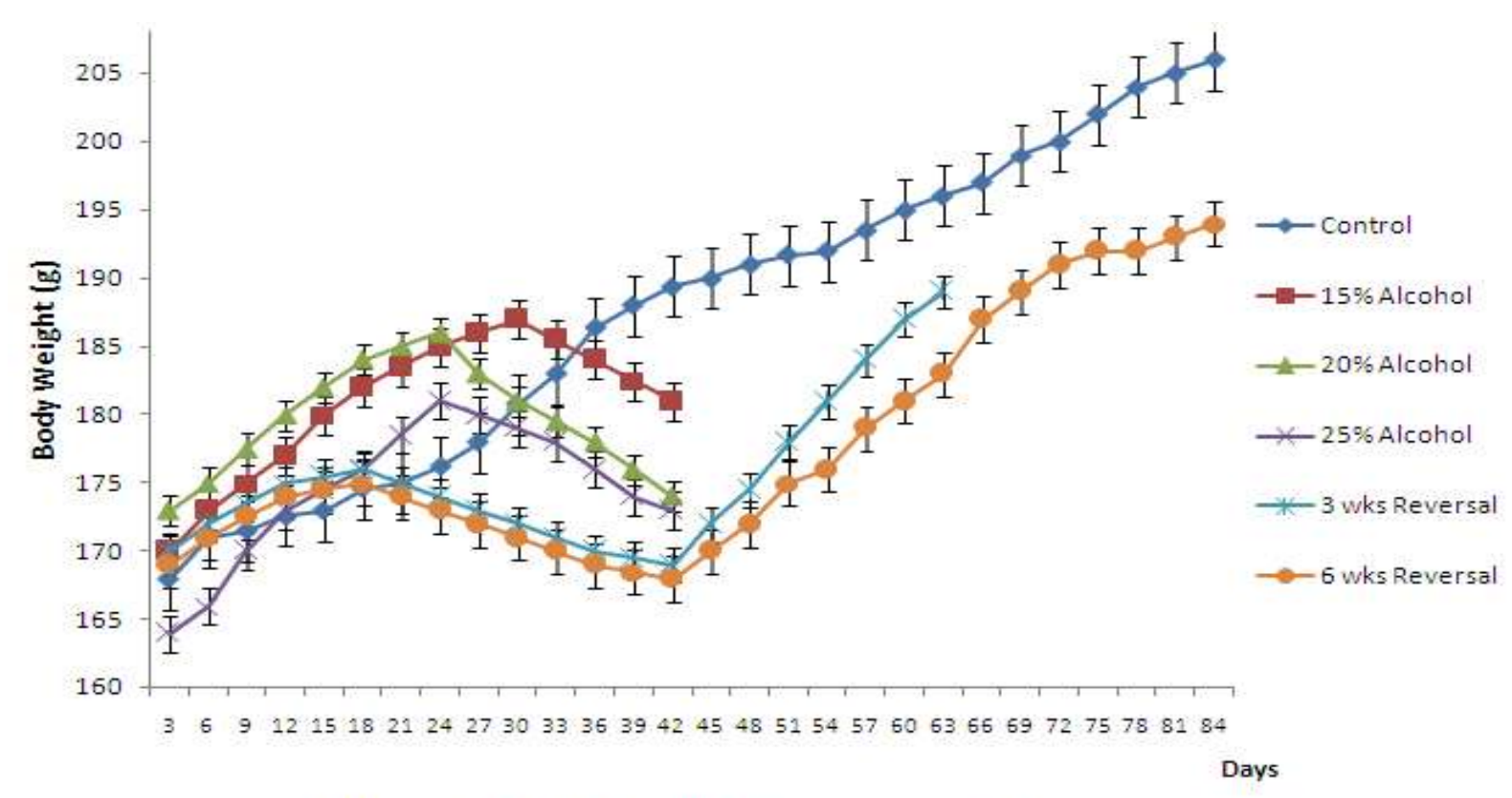

Fig 1: Effect of Alcohol on the bodv weight of rats ( $n=6$ )

The above figure show that the body weights of the control rats increased progressively throughout the experimental period. The body weight of the $15 \%$ alcohol treated rats increased up to the $30^{\text {th }}$ day while the body weight of $20 \%$ and $25 \%$ alcohol treated rats increased till the $24^{\text {th }}$ day, after which their weights decreased progressively till the end of the experiment. The reversal groups experienced initial reduction and then subsequently increase in body weight

\section{Effect of alcohol on Clotting time}

In this experiment, the effect of alcohol on the clotting time of the Wistar rats were determined. The mean clotting time in the control group was $2.50 \pm 1.70 \mathrm{~s}$ while those of group $\mathrm{B}, \mathrm{C}$ and $\mathrm{D}$ were $2.88 \pm 1.90,3.1$ \pm 1.02 and $3.35 \pm 4.18$ mins respectively as shown in fig 2 . The alcohol caused a dose dependent increase in the clotting time, as the alcohol concentration increased, the clotting time increased. The increase was significant $(\mathrm{p}<0.05$ ) when $20 \%$ and $25 \%$ alcohol were compared with control. Though $15 \%$ alcohol increased the clotting time when compared with control, the increase was not significant.

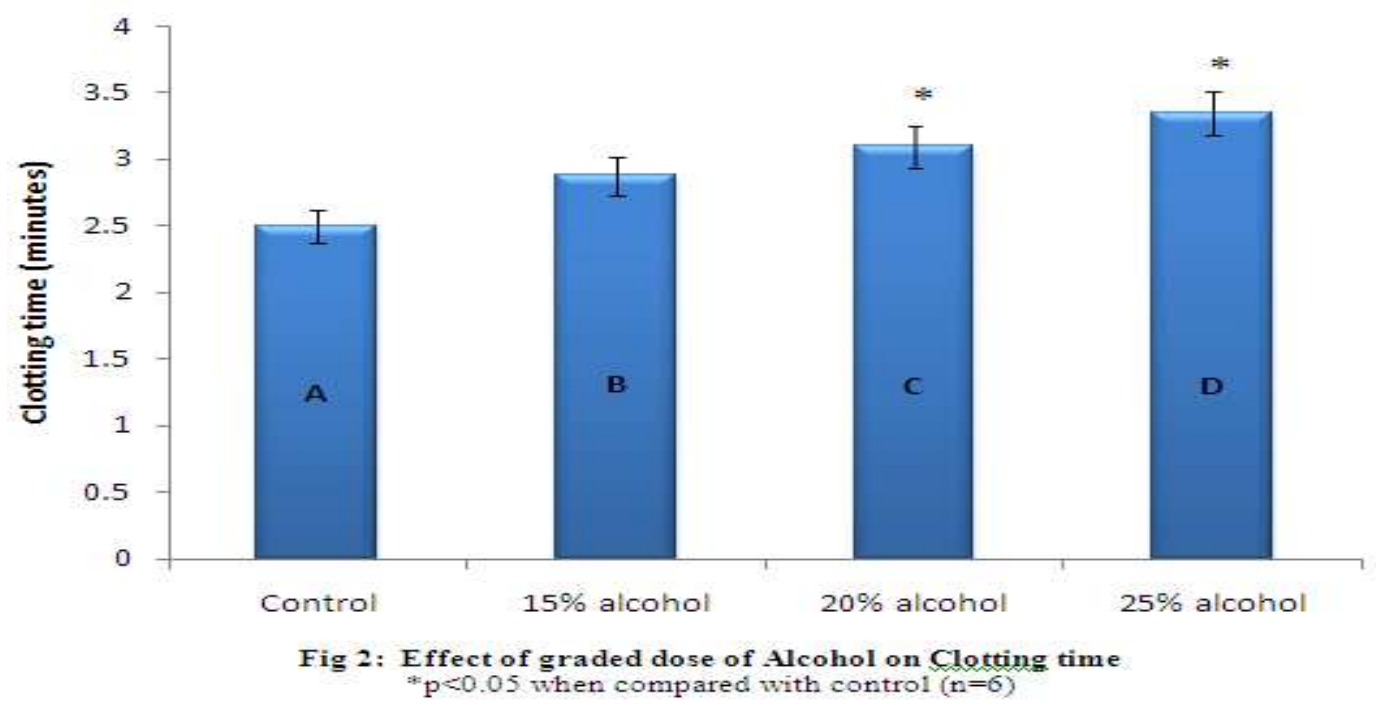

\section{Reversal effect on clotting time after alcohol treatment}

After the withdrawal of alcohol the mean clotting time in the control group was $2.50 \pm 16.70$ mins while those of group D, E and F were $3.35 \pm 4.18,2.83 \pm 1.20$ and $2.76 \pm 1.8$ mins respectively as shown in fig 3 . There was no significant difference in the clotting time in the reversal groups when compared with the control group. The rate of decrease in clotting time was dependent on duration of alcohol withdrawal. 


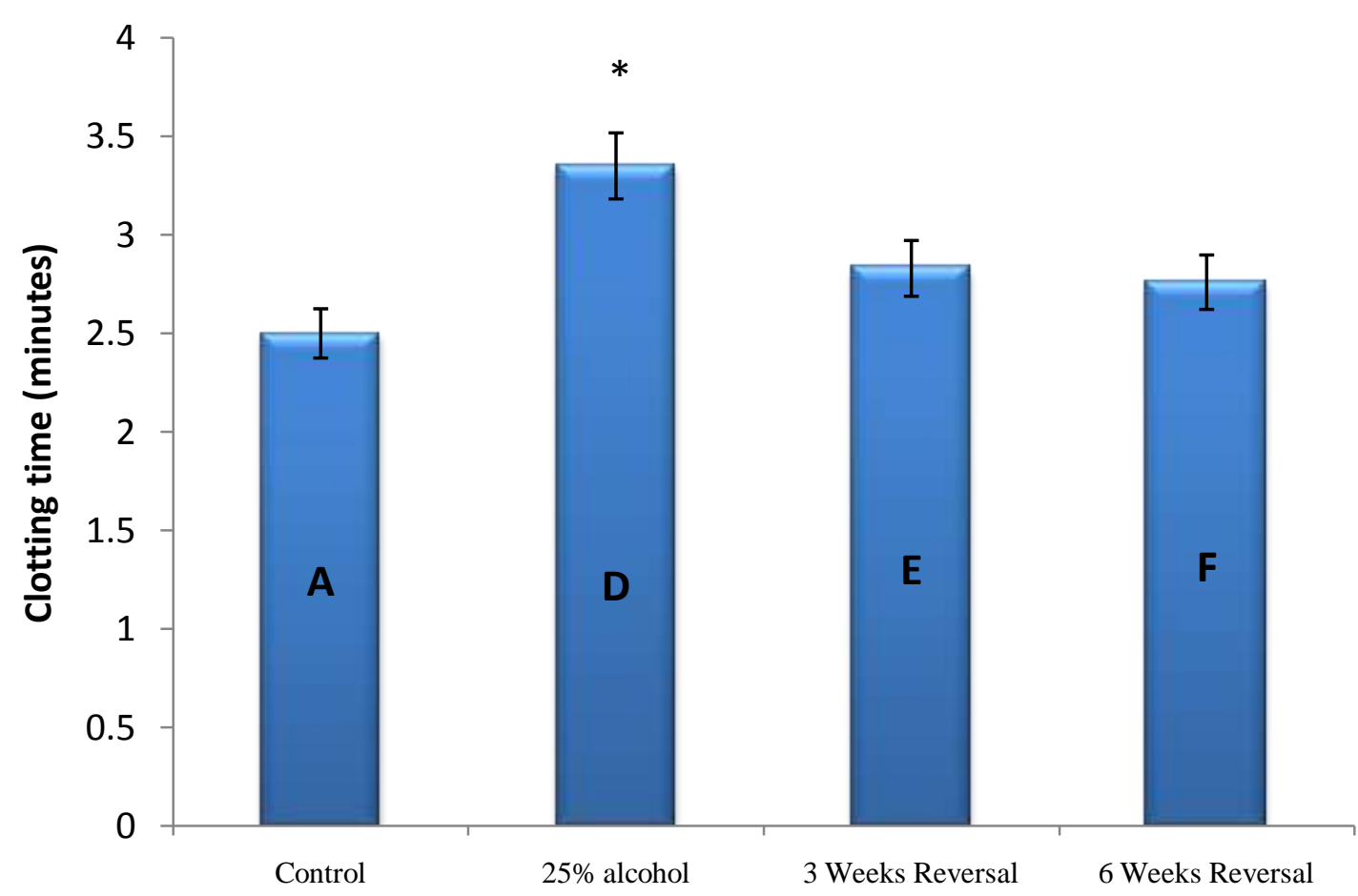

Fig 3: Clotting time after withdrawal of Alcohol treatment ${ }^{*} \mathrm{p}<0.05$ when compared with control $(\mathrm{n}=6)$

\section{Discussion}

Major epidemiological studies show that moderate alcohol consumption leads to a decrease in the morbidity and mortality from CAD (Moore and Pearson, 1986; Yano et al., 1977). Alcohol may stimulate fibrinolysis (Hendriks et al, 1994) and decrease coagulation (Dimmitt et al, 1998), it might also decrease inflammatory processes (Imhof et al, 2001; Koenig et al, 1999). In this study, alcohol consumption at different doses decreased the body weight within six weeks. This could probably suggest that the metabolic activity from oxidation of alcohol could inhibit body metabolism or feeding pattern in the rats. Observation from prior studies supports this claim that alcohol caused reduction in the body weight, with Osonuga et al. (2010) reporting a non significant reduction in the body weight of rats. Blood clotting is important during situations of bleeding, this result from platelets aggregation. Findings from this study have shown that alcohol concentration significantly $(\mathrm{p}<0.05)$ increased the clotting time in the animals in a dose dependent manner. This fact can be understandable with reports from Haut and Cowan (1974) showing the effect of alcohol on platelet activity. They demonstrated that alcohol added to human platelets in vitro, ingested by subjects, or infused intravenously into men markedly decreased platelet aggregation in response to thrombin, collagen, epinephrine, and adenosine-5'-diphosphate (ADP). Further studies from Renaud et al. (1984) showed that platelet aggregation in response to ADP and collagen decreased as the frequency of alcohol consumption increased. Krobot et al. (1992) in a cross-sectional study showed that increased consumption of alcohol decreased the fibrinogen concentration. The reduction of this coagulation factors concentration due to the increase in the dose of alcohol could possibly explain the reason behind the delay in blood clotting and hence increase in clotting time as seen in this study. This study further showed that withdrawal of alcohol will reduce the clotting time back to normal after a duration of time, and therefore it has demonstrated that though alcohol causes detrimental effect on clotting time and in the long run affecting bleeding, but withdrawal from alcohol intake would ameliorate this effect.

\section{Conclusion}

Though moderate alcohol intake have shown beneficial effect, administration of different doses of alcohol have caused increase in the clotting time and hence greater amount of time it takes to stop bleeding which could be dangerous in the maintenance of hemostasis especially in individuals undergoing surgery. 


\section{References}

[1] Dimmitt SB, Rakic V, Puddey IB. The effects of alcohol on coagulation and fibrinolytic factors: a controlled trial. Blood Coagul Fibrinolysis. 1998. 9:39-45.

[2] Friedman L.A. Kimball AW. Coronary heart disease and alcohol consumption in Framingham. Am J Epidemiol. 1986. 124: 481 9.

[3] Haut MJ, Cowan DH. The effect of ethanol on hemostatic properties of human blood platelets. Am J Med. 1974. 56:22-33.

[4] Hillbom M, Neiman J. (). Platelet thromboxane formation capacity after ethanol withdrawal in chronic alcoholics. Haemostasis. 1988. 18:170-178

[5] Klatsky AL, Armstrong MA, Friedman GD. Alcohol and mortality. Ann Intern Med. 1992. 117: 646 - 54.

[6] Krobot K, Hense HW, Cremer P, Determinants of plasma fibrinogen: relation to body weight, waist-to-hip ratio, smoking, alcohol, age, and sex; results from the second MONICA Augsburg survey 1989-1990. Arterioscler Thromb. 1992. 12:780-788.

[7] Lazarus NB, Kaplan GA, Cohen RD. Change in alcohol consumption and risk of death from all causes and from ischaemic heart disease. Br Med J. 1991. 303:553-556.

[8] Meade TW, Mellows S, Brozovic M. Haemostatic function and ischaemic heart disease: principal results of the Northwick Park Heart Study. Lancet.; 1986. 2:533-537.

[9] Mikhailidis DP, Jenkins WJ, Barradas MA. Platelet function defects in chronic alcoholism. Br Med J (Clin Res Ed). 1986. 293:715718 .

[10] Moore RD, Pearson TA. Moderate alcohol consumption and coronary artery disease: a review. Medicine (Baltimore) 1986. 65:242267.

[11] Myreng Y, Aursnes I, Hjermann I. von Willebrand factor and cardiovascular risk. Thromb Res. 1986. 41:867-871.

[12] Renaud S, De Lorgeril, M. Wine, alcohol, platelets and the French paradox for coronary heart disease. Lancet. 1992. $339: 1523$ - 6.

[13] Renaud S, McGregor L, Martin J. Influence of alcohol on platelet function in relation to atherosclerosis. In: Pozza G, Micossi P, Catapano AL, et al, eds. Diet, Diabetes, and Atherosclerosis. New York, NY: Raven Press. 1984. 177-187.

[14] Sugrue DD, Trayner I, Thompson GR. Coronary artery disease and haemostatic variables in heterozygous familial hypercholesterolaemia. Br Heart J. 1985. 53:265-268.

[15] Wilhelmsen L, Svardsudd K, Korsan-Bengtsen R. (1984): Fibrinogen as a risk factor for stroke and myocardial infarction. N Engl J Med. 1984. 311:501-505.

[16] Yano K, Rhoads GG, Kagan A. Coffee, alcohol and risk of coronary heart disease among Japanese men living in Hawaii. N Engl J Med. 1977. 297:405-409.

[17] Dare, W.N., Noronha, C.C., Kusemiju, O.T. and Okanlawon, O.A. The effect of Ethanol on Spermatogenesis and Fertility in male Sprague - Dawley Rats pretreated with acetylsalicylic acid. Nig. Postgrad. Med. J. 2002. 9(4):194-98.

[18] Osonuga, O. A., Osonuga, O. I., and Osonuga, A. A. Deleterious effects of ethanol on hematological parameters and fertility in albino rats. Asian J. Med. Sci. 2010. 1: 37-40.

[19] Hendriks HFJ, Veenstra J, Velthuis-te Wierik EJM, Schaafsma G \& Kluft C. Effect of moderate dose of alcohol with evening meal on fibrinolytic factors. Br. Med. J. 1994. 308, 1003 - 1006.

[20] Imhof A, Froehlich M, Brenner H. Effect of alcohol consumption on systemic markers of inflammation. Lancet 2001. 357:763-7.

[21] Koenig W, Sund M, Fro“hlich M, Fischer HG, Lowel H, Doring A, Hutchinson WL \& Pepys MB. C-Reactive protein, a sensitive marker of inflammation, predicts future risk of coronary heart disease in initially healthy middle-aged men. Circulation. 1999. 99 , $237-242$. 